\title{
AGEING TESTS ON GOLD LAYERS AND BONDED CONTACTS
}

\author{
H. HIEBER, F. BETKE and K. PAPE \\ Philips GmbH Forschungslaboratorium Hamburg, 2000 Hamburg 54, Federal Republic of Germany
}

(Received May 31, 1977)

Studies have been made of the adhesion of gold thin films on $\mathrm{NiCr}$ and Mo layers deposited on ceramic substrates. It is shown that the ageing behaviour and the related long-term adhesion losses are complex processes and the various contributing mechanisms are identified.

\section{INTRODUCTION}

Searching for physical reasons for the degradation of integrated circuits, we find that the weak links are often the thin-film metallizations, the bonded or soldered contacts, and the hybrid metallizations. The metal layers mainly limit the lifetime of the microelectronic devices during their application.

Several attempts have been made to undertake an analysis of the degradation kinetics of gold thin and thick films which is closely related to the material structure. ${ }^{1,2}$ This is in contrast to the analysis of statistical reliability, where usually a black box analysis of the electronic beitaviour of a device leads to probability data. ${ }^{3}$

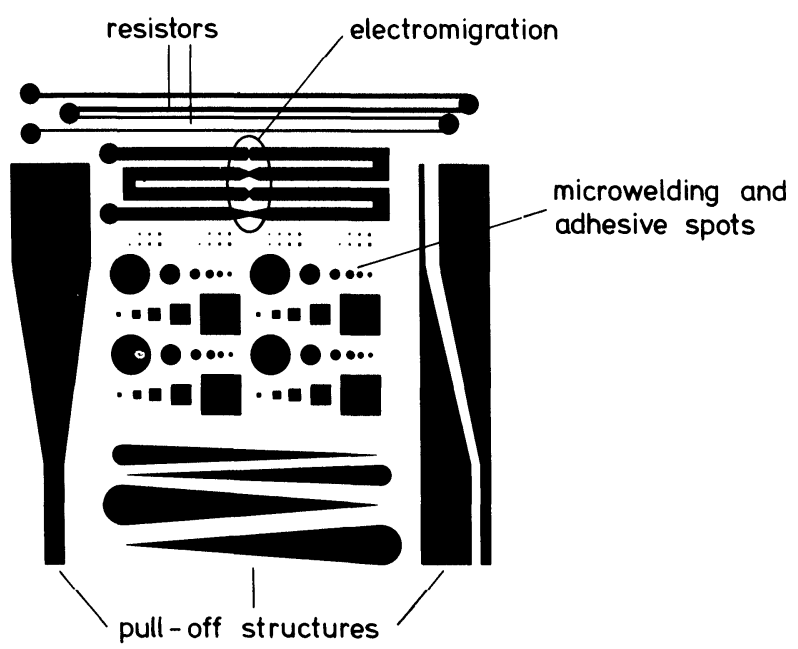

FIGURE 1 The test pattern, used for ageing measurements by DC resistivity and adhesion tests
All material failure is dynamic. It advances by rate processes which have threshold conditions and characteristic growth kinetics. ${ }^{4}$ In particular, the physical properties of $\mathrm{Au}$ thin films change during their life time under the influence of various factors,

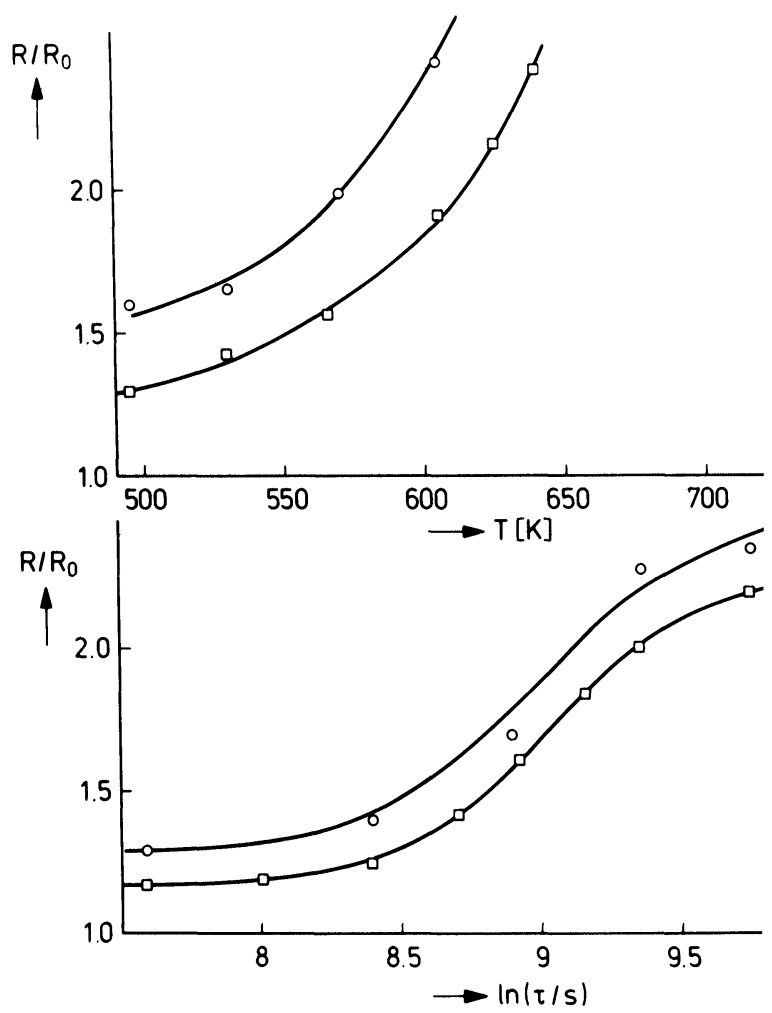

FIGURE 2 Resistivity changes of a sputtered $0.5 \mu \mathrm{m} \mathrm{Au}$ layer on a $50 \mathrm{~nm} \mathrm{NiCr}$ adhesion layer. $\square=$ heat treatment without electromigration; $\mathrm{O}=$ heat treatment with electromigration (1.1 x 107 $\mathrm{A} \mathrm{cm}^{-2} \mathrm{DC}$ current density) 
such as the grain size, the lateral homogeneity of the grain structure, the chemical composition, the defect accumulation at the free surface and the interfaces, and finally the mechanical stresses.

Knowledge about the processes concerning the ageing nuakes it possible to establish a thermodynamical calculation for simple cases e.g. like the recovery of defects ${ }^{1}$ or the diffusion of humidity through encapsulations ${ }^{5}$ the latter of which is thought to govern layer degradation by corrosion. In Section 2 of this paper we shall describe the structural defect dependent ageing processes in pure and sandwich layers of $\mathrm{Au}$.

The term "ageing" is used to describe variation with time, temperature and electrical stress which produces irreversible change in physical and chemical properties during the treatment. In Section 3 the problem of the adhesion between the layers and the subsirate will be discussed in terms of the ageing kinetics.

\section{THE AGEING KINETICS OF GOLD LAYERS}

Pure, fine-grained fcc. metal films with a thickness of the order of $0.5 \mu \mathrm{m}$ to $3 \mu \mathrm{m}$ have, in contrast to the respective bulk metals, a high density of atomistic defects. This is expressed in terms of a high internal stress $^{6}$ and of a high dislocation density. ${ }^{7}$ Both show high rates of recovery, due to diffusion and transformation in the crystalline structure, at temperatures below the bulk recrystallization temperature of $300-360^{\circ} \mathrm{C}$ for pure gold. ${ }^{8}$

For a precise determination of the ageing kinetics using the MEECHAN-BRINKMAN (M-B) method, ${ }^{9}$ the $\mathrm{DC}$ resistivity is a useful physical property: it is

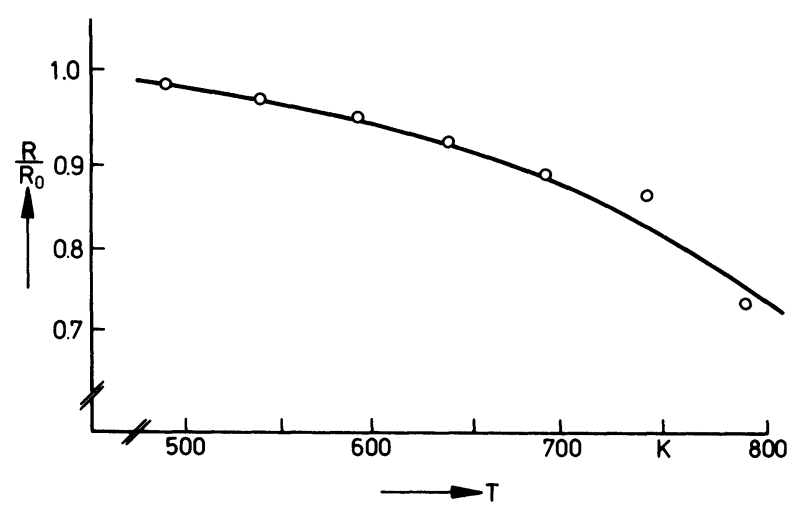

FIGURE 3 Resistivity decrease of a sputtered $0.5 \mu \mathrm{m} \mathrm{Au}$ layer on a $50 \mathrm{~nm}$ Mo adhesion layer

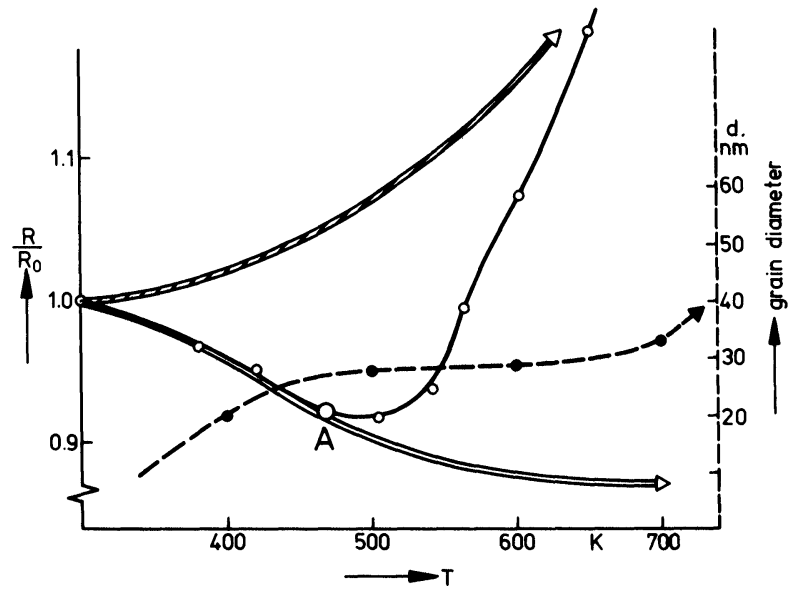

FIGURE 4 Resistivity change of an evaporated $5 \mu \mathrm{m} \mathrm{Au}$ layer

$$
\begin{aligned}
O & =\text { measured values } \\
\bullet & =\text { the grain coarsening of thin } \mathrm{Au} \text { layers (right scale) } \\
\Longrightarrow & =\text { resistivity decrease due to recovery } \\
\Rightarrow & =\text { resistivity increase due to } \mathrm{Cr} \text { diffusion into the } \mathrm{Au}
\end{aligned}
$$

sensitive to the defect concentration and it is measured in a simple way with high accuracy. ${ }^{\prime}$

The applied test pattern, Figure 1, contains strips with different cross sections. The two configurations with wide strips are used for investigating the electromigration kinetics. The narrow strips are used for the DC measurements. The other sections of the test pattern contain square and round spots used for adhesion tests on bonded contacts, and areas for diffusion tests using electron microprobe analysis.

The DC measurements were carried out at $78 \mathrm{~K}$ (liquid nitrogen) after each isochronal (increasing temperature and constant time interval) and isothermal (increasing time, constant temperature) heat treatment. ${ }^{1}$ The classification of the measured

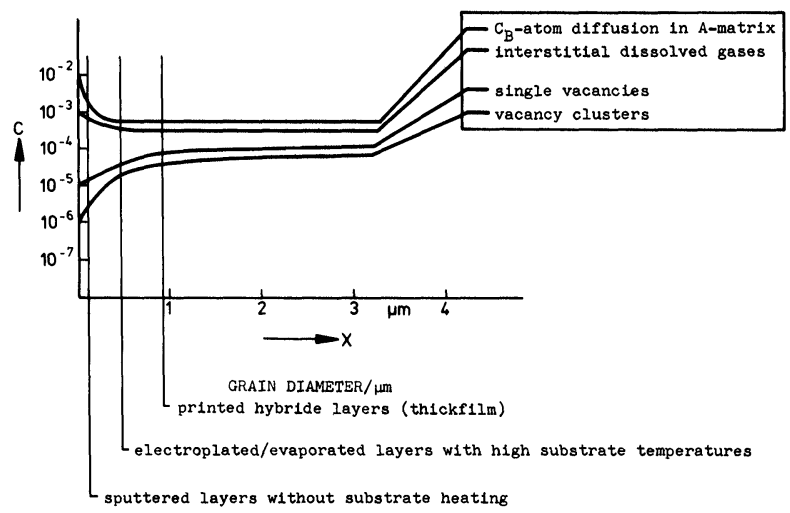

FIGURE 5 Structure defect concentrations beneath high angle grain boundaries ${ }^{15}$ 


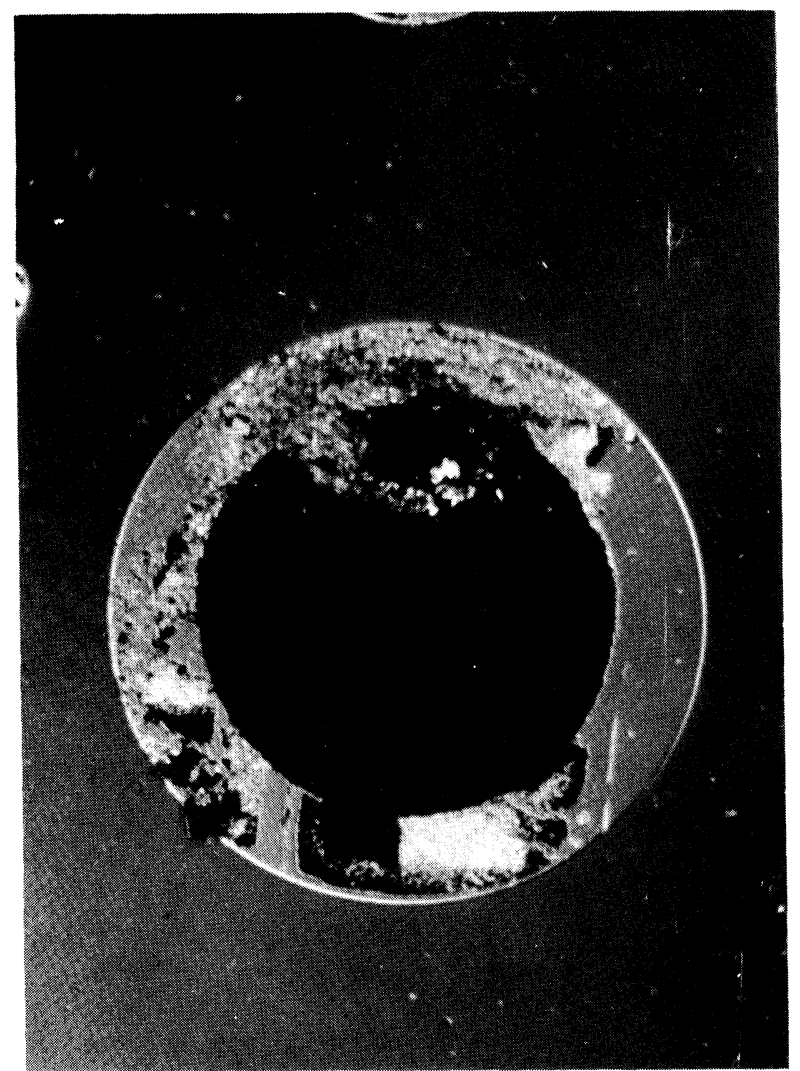

FIGURE 6 The corrosion of an adhesion layer of $50 \mathrm{~nm} \mathrm{Ti}$ under a $0.1 \mu \mathrm{m}$ sputtered Au layer (spot diameter $1 \mathrm{~mm}$ )

resistivity variations leads to the following types of behaviour:

- The diffusion sensitive systems, e.g. Au thin films with $\mathrm{NiCr}$ adhesion layers show a remarkable increase in the DC resistivity during the isochronal heat treatment, Figure 2 . This is explained by the diffusion of adhesion layer components into the pure gold layer. It should be noted that an additional DC current during the heat treatments increases the residual resistivity. In this case, additional defects near grain boundaries are introduced, the diffusion of the $\mathrm{Ni}$ and $\mathrm{Cr}$ into the $\mathrm{Au}$ is not markedly disturbed.

- The non-diffusion sensitive systems show a continuous decrease of the DC resistivity within the limits of a few percent. Figure 3 shows the behaviour of a $0.5 \mu \mathrm{m}$ Au thin film on a $50 \mathrm{~nm}$ Mo adhesion layer. In the bulk we do not find any solid state miscibility. The recent observations of the diffusion of Mo through Au layers ${ }^{10}$ must be interpreted by grain boundary diffusion.
Thus we find two basic kinds of behaviour which govern, in a more or less complex manner, the ageing characteristics of the measured systems, Au layer/ adhesion layer. If the diffusion and the recovery both contribute to the change in the DC resistivity, the resulting plots can be separated to show the contributions. Figure 4 shows the ageing kinetics of a $5 \mu \mathrm{m}$ thick $\mathrm{Au}$ film on a very thin $\mathrm{Cr}$ adhesion layer in the temperature range up to $350^{\circ} \mathrm{C}$. At lower temperature, the recovery of $\mathrm{Au}$ vacancies near the grain boundaries takes place. ${ }^{1}$ Above the point $A\left(T \cong 200^{\circ} \mathrm{C}\right)$, the mobility of the $\mathrm{Cr}$ atoms predominates and leads to increasing DC resistivity (the diffusion coefficient of the low-concentrated $\mathrm{Cr}$ in the $\mathrm{Au}$ matrix is

$$
\left.D=1.5 \times \exp -(0.4 \pm 0.06) / k T) \mathrm{~cm}^{2} \mathrm{~s}^{-1}\right)
$$

The diffusion of $\mathrm{Cr}$ (and of $\mathrm{Ni}$ ) from the $\mathrm{NiCr}$ adhesion layers into the Au thin films can be examined by electron microprobe analysis of the thin Au films. The mass center of the adhesion layer elements shifts upwards from the original position into the volume of the Au layer. For example, in a $0.1 \mu \mathrm{m}$ thick $\mathrm{Au}$ layer on a $10 \mathrm{~nm} \mathrm{NiCr}$ adhesion layer, the original ratios between the characteristic X-ray intensities are:

$$
\operatorname{Au}\left(M \alpha_{1}\right): \operatorname{Cr}(K \alpha): \operatorname{Ni}(K \alpha)=1: 0.105: 0.044
$$

A heat treatment by continuous temperature increase from $155^{\circ} \mathrm{C}$ to $325^{\circ} \mathrm{C}$ in vacuum in $1.6 \mathrm{~h}$, leads to an increase of the relative $\mathrm{Cr}$ and $\mathrm{Ni} \mathrm{X}$-ray signals:

$$
\operatorname{Au}\left(M \alpha_{1}\right): \operatorname{Cr}(K \alpha): \operatorname{Ni}(K \alpha)=1.0: 0.126: 0.060 .
$$

This corresponds to diffusion coefficients of $5 \times 10^{-11} \mathrm{~cm}^{2} \mathrm{~s}^{-1}$ and $\gtrsim 10^{-9} \mathrm{~cm}^{2} \mathrm{~s}^{-1}$ for $\mathrm{Cr}$ and $\mathrm{Ni}$ respectively at $T=200^{\circ} \widetilde{\widetilde{C}}$. These values are in agreement with observations of the surface concentration of $\mathrm{Cr}$ in $\mathrm{Au}$ by other physical methods. ${ }^{10,11}$

The kinetics of the observed ageing process in $\mathrm{Au}$ thin films which react with the adhesion layers and change their own defect distributions become still more complex if we take into consideration the equilibrium defect distribution near free surfaces and grain boundaries (Figure 5.) The ageing analysis using the $\mathrm{M}-\mathrm{B}$ method gives values of the activation energies of the predominant reaction of the lattice defects.

\section{ADHESION LOSSES OF BONDED CONTACTS}

If the adhesion layers react by diffusion with the $\mathrm{Au}$ layers, the residual gold-rich interface to the oxide 


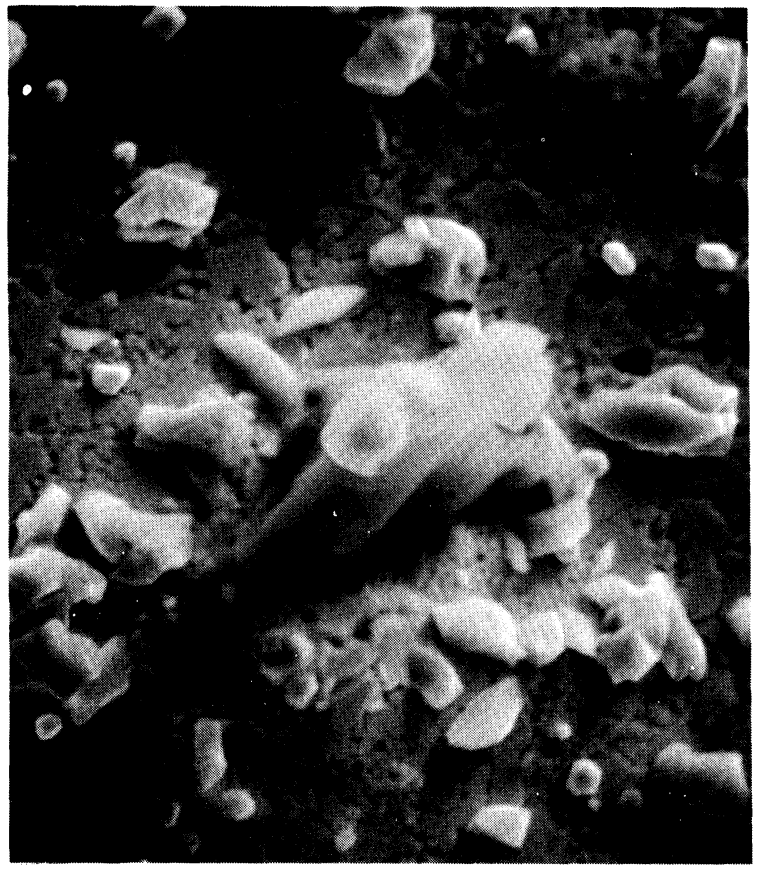

FIGURE 7 Crystallization effects in a $0.5 \mu \mathrm{m} \mathrm{Au} \mathrm{nm}$ $\mathrm{Ti} / \mathrm{SiO}_{2}-\mathrm{Si}$ substrate system

(a) chemical reaction products of $T i$-silicate (length of bottom edge $=34 \mu \mathrm{m}$ )

(b) vaulting of a structred layer system (length of side of square $=0.75 \mathrm{~mm}$ )

(c) crystal growth through the Au layer (length of bottom edge $=17 \mu \mathrm{m})$

substrate does not have sufficient adhesion. Consequently the "adhesion" must be related to the time and temperature dependent longterm ageing kinetics. ${ }^{12}$ The term "adhesion" is to be understood as the mechanical resistance which a multilayer structure consisting of a thin film and a substrate has to "pull-off," blistering and other irreversible kinds of destruction.

In this section we do not consider the zero-hour adhesion which can be related closely to fracture mechanics. The long term adhesion is based on the creep fracture of composite structures involving the influence of corrosion at the crack tip. The adhesion layer also reacts chemically with the oxide substrate. Figure 6 shows the corrosion in the flaw between the substrate and the Au layer. Figures $7 a, b$ show the formation of crystals out of the plane of the adhesion layer. These chemical reaction products are growing through the Au layer (Figure 7c). It should be noted that these reactions of crystalline transformation are not stress dependent as in the case of the whisker growth through a hard cover layer. ${ }^{13}$ (The driving
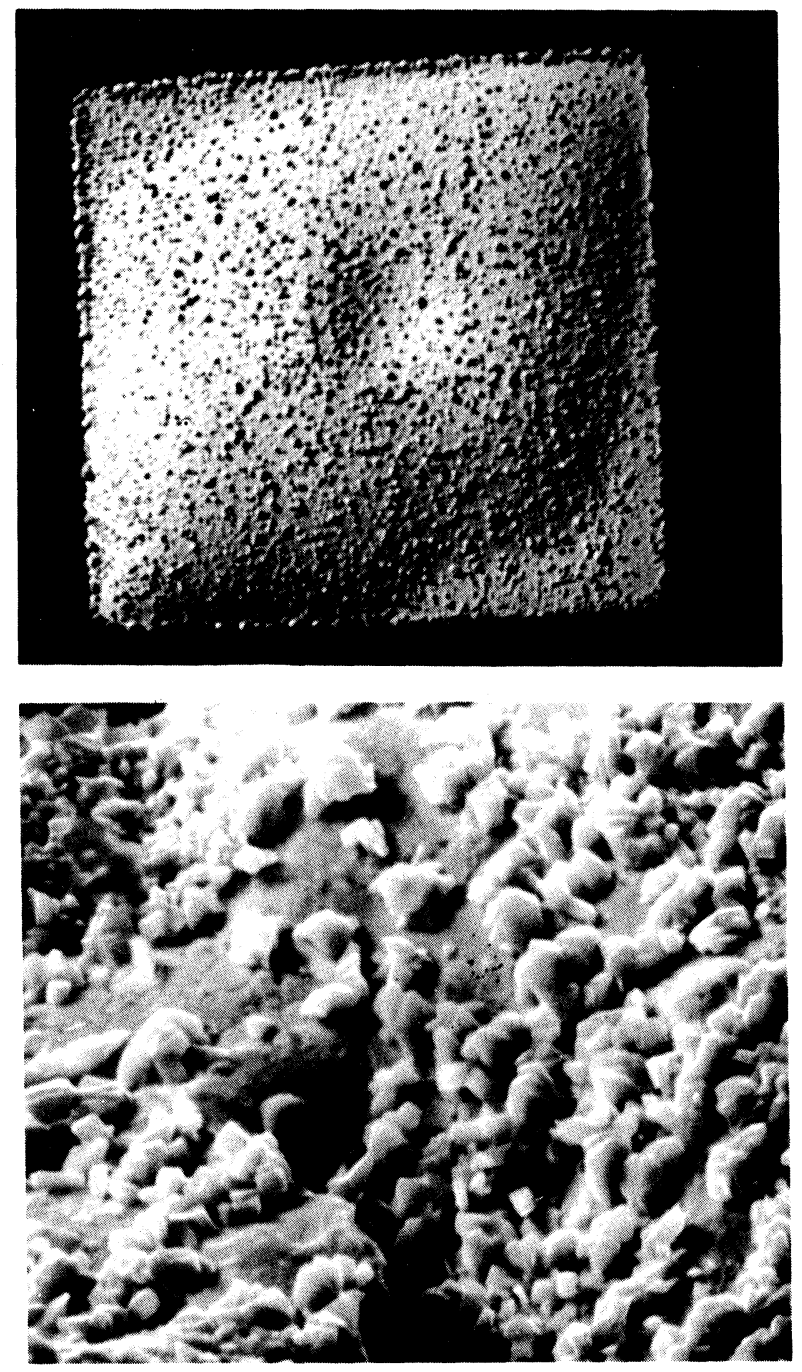

force originates from the loss in the free enthalpy by means of the large crystal formation.)

The effect of an externa! tensile force e.g. attached to a microwelded beam lead is shown diagrammatically in Figure 8. ${ }^{12}$ The different geometrical relationships of the arrangement consisting of the substrate/thin film/beam lead system lead to different kinds of tensile stress distributions.

The sharper the crack tip the higher will be the local maximum of the normal stress in the thin film. Table I shows the lifetimes of diffusion sensitive adhesion layer/Au layer systems which were contacted by thermocompressive beam lead bonds and subjected to steady-state creep tests.

The diffusion governed process of the adhesion loss by sharp crack propagation is explained by the 
TABLE I

The limits of lifetime of beam lead bonded $\mathrm{Au}$ thin films with diffusion sensitive adhesion layers on $\mathrm{Si}-\mathrm{SiO}_{2}$ substrates

\begin{tabular}{|c|c|c|c|c|}
\hline $\begin{array}{l}\text { Au thinfilm, } \\
\text { thickness } \\
{[\mu \mathrm{m}]}\end{array}$ & $\begin{array}{l}\text { Adhesion } \\
\text { layer, thickness } \\
{[\mathrm{nm}]}\end{array}$ & $\begin{array}{l}\text { Mechanical } \\
\text { stress } \\
{[M P a]}\end{array}$ & $\begin{array}{l}\text { Temperature } \\
\text { range } \\
{\left[{ }^{\circ} \mathrm{C}\right]}\end{array}$ & $\begin{array}{l}\text { Lifetime } \\
\text { limits } \\
{[h]}\end{array}$ \\
\hline 0.50 & $\mathrm{NiCr}, 50$ & $\begin{array}{r}2 \\
2 \\
10 \\
10\end{array}$ & $\begin{array}{r}250 \text { to } 300 \\
30 \text { to } 100 \\
250 \text { to } 300 \\
30 \text { to } 100\end{array}$ & $\begin{aligned} 9 & \pm 2.5 \\
100 & \pm 30 \\
4 & \pm 1.5 \\
12 & \text { to } 20\end{aligned}$ \\
\hline 0.10 & $\mathrm{NiCr} 10$ & $\begin{array}{l}2 \\
2 \\
6\end{array}$ & $\begin{array}{r}120 \text { to } 200 \\
30 \text { to } 80 \\
30 \text { to } 80\end{array}$ & $\begin{array}{l}2.2 \pm 0.5 \\
10 \pm 2 \\
\leqslant 6\end{array}$ \\
\hline 0.10 & $\mathrm{Ti} \quad 10$ & $\begin{array}{l}2 \\
6\end{array}$ & $\begin{array}{l}200 \text { to } 300 \\
100 \text { to } 200\end{array}$ & $\begin{array}{l}6 \text { to } 60 \\
5 \text { to } 50\end{array}$ \\
\hline
\end{tabular}

model shown in Figure 9. The creep stability of the fine grained thin film is governed by the grain boundary creep rate. This is accompanied by creep induced diffusion of the adhesion layer elements through the grain boundaries in the gold. The kinetics is determined by the vacancy migration shown in Figure 9. This leads to a steady-state creep rate $\dot{\epsilon}$ given by

$$
\dot{\epsilon}=\frac{2 \delta \sigma \Omega}{k T R^{3}} \frac{D_{1} D_{2}}{n_{2} D_{1}+n_{1} D_{2}}:
$$

where $\delta=$ width of the grain boundary, $\sigma=$ shear stress, $\Omega=$ average atomic volume, $R=$ grain radius, $D_{1}=$ diffusity of Au vacancy, $D_{2}=$ diffusity of the adhesion layer element in $\mathrm{Au}, n_{1}, n_{2}=$ initial concentration of the components.

Using the simplification that no chemical bonds are ruptured in the cracking interface, we get, for the example of Au grains (with $R \cong 100 \mathrm{~nm}, d \cong 0.3 \mathrm{~nm}$, $\Omega=0.007 \mathrm{~nm}^{3}, \sigma=10 \mathrm{MPa}, T=300-400 \mathrm{~K}$,) and $\mathrm{Cr}$ as the tracer diffusor, (the grain boundary self diffusivity of $\mathrm{Au} D_{1}$ as in Gupta reference, ${ }^{2}$ the $\mathrm{Cr}$ diffusivity in $\mathrm{Au} \mathrm{D}_{2}$ as in Holloway reference: ${ }^{14}$

$$
\dot{\epsilon}=3 \times 10^{-10} \mathrm{~s}^{-1}-3 \times 10^{-7} \mathrm{~s}^{-1} \text {, }
$$

if we assume grain boundary occupation densities of between 0 and $10 \%$.

The whole system consisting of the beam lead with a)
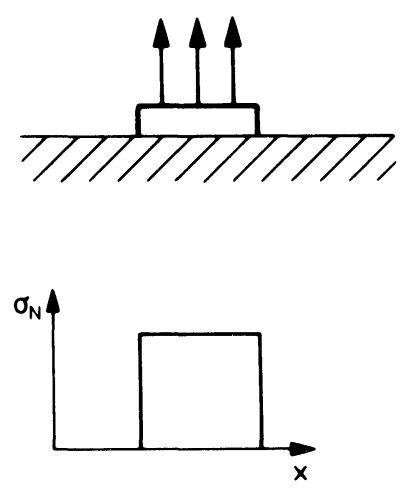

b)


c)
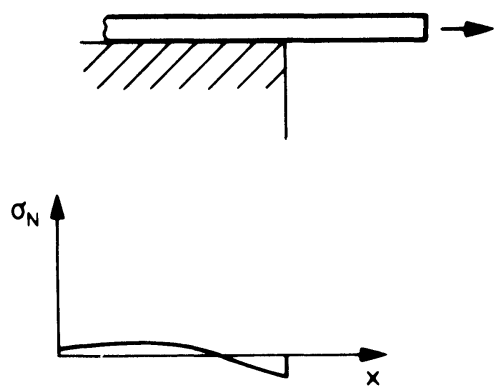

FIGURE 8 Stress distributions for different directions of force introduction

a) pure normal stress

b) stress maximum at the crack tip

c) bending of the beam leads to higher shear and lower normal stress 

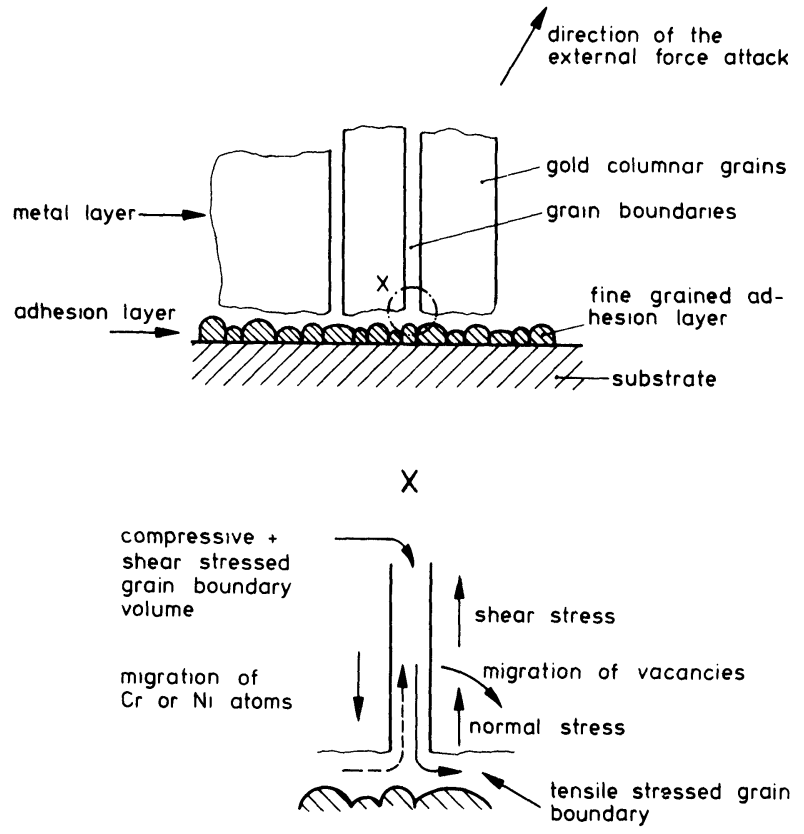

FIGURE 9 The mechanism of grain boundary creep assisted by the segregation of the adhesion layer material in the Au layer grain boundaries.

a curvature radius of $\approx 0.4 \mathrm{~mm}$ and a thickness of $0.1 \mathrm{~mm}^{12}$ will provide crack velocities between $10^{-9} \mathrm{~mm} \mathrm{~s}^{-1}$ and $10^{-6} \mathrm{~mm} \mathrm{~s}^{-1}$. The total crack lengths of 0.2 to $0.35 \mathrm{~mm}$ yield lifetimes between $2 \mathrm{~h}$ at $T=400 \mathrm{~K}$ and several days at $T=300 \mathrm{~K}$. This is in a good agreement with the experimental results.

\section{CONCLUSIONS}

It is evident that the ageing kinetics of an $\mathrm{Au}$ thin film/adhesion layer composite and the related long term adhesion losses are complicated effects which result from the occurrence of several reactions, namely:-

- the recovery of atomistic defects
- the diffusion of the adhesion layer elements into the gold thin films

- the stress-induced grain boundary creep

- the chemical reaction of the adhesion layer.

The layer thicknesses, the grain and the atomistic defect structure, and the geometry of the introduced external force determine the kinetics of the thin film degradation and of the adhesion losses.

\section{REFERENCES}

1. H. Hieber, Ageing properties of gold layers with different adhesion layers, Thin Sol. Films, 37, 335 (1976).

2. D. Gupta, Grain-boundary selfdiffusion in $\mathrm{Au}$ by $\mathrm{Ar}$ sputtering technique, J. Appl. Phys. , 44, 4455 (1973).

3. K. J. Young, Microelectronics and Reliability, 9, 133 (1970).

4. D. R. Curran, L. Seaman, D. A. Shockey, Dynamic failure in solids, Physics Today, 46, Jan. 1977.

5. A. V. Ferris-Prabhu, Application of diffusion kinetics to reliability, Phys. Stat. Sol. (a), 32, 239 (1975).

6. C. A. O. Henning, F. W. Boswell, J. M. Corbett, Mechanical properties of vacuum-deposited metal films. I. Copper films fcc metal films - III. Layered $\mathrm{Cu}$ and $\mathrm{Ni}$ single crystal composites, Acta metallurg., 23, 177, 193 (1975).

7. A. Gangulee, Strain-relaxation in thin films on substrates, Acta metallurg., 22, 177 (1974).

8. M. C. Quintana, J. L. Sacedon, J. Mendiola, Recrystallization on their substrates of $\mathrm{Au}(001) \mathrm{NaCl}$ films into $\mathrm{Au}$ (111) NaCl, Thin Sol. Films, 17, 319 (1973).

9. J. C. Meechan, J. A. Brinkman, Thermal analysis of chemical reaction, Phys. Rev., 103, 1193 (1956).

10. G. H. Gilmer, H. H. Farrell, Grain-boundary diffusion in thin films. O. The isolated grain boundary., J. Appl. Phys., 47, 3792 (1976).

11. A. Munitz, Y. Komen, Structural and resistivity changes in heat treated Cr-Au films, Thin Sol. Films, 37, 171 (1976).

12. H. Hieber, H. Berndt, On the Adhesion Behaviour of Thin Films with Thermocompression Bonds, Schriftenreihe Deutscher Verband für Schweißtechnik, Düsseldorf, Band 40, 118 (1976).

13. I. A. Blech, P. M. Petroff, K. L. Tai, V. Kumar, Whisker growth in Al thin film, J. Cryst. Growth, 32, 161 (1975).

14. P. J. Holloway, D. E. Amos, G. C. Nelson, Analysis of grainboundary diffusion in thin films, J. Appl. Phys., 47, 3769 (1976).

15. R. E. Hannemann, T. R. Antony, Der einflu $\beta$ der nichtgleichgewichts-entmischung auf die oberflächennahe diffusion, Acta metallurg., 17, 1133 (1969). 

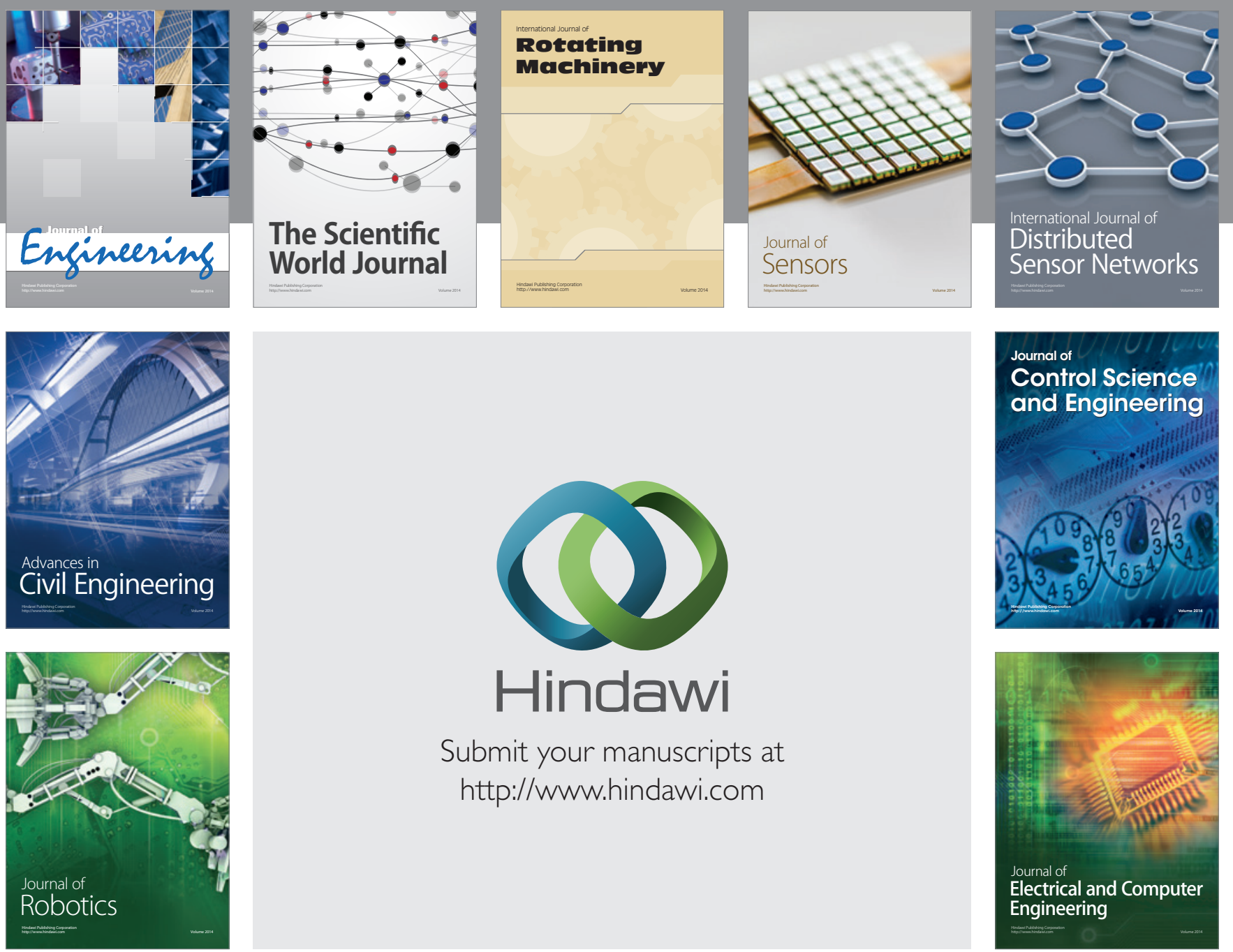

Submit your manuscripts at

http://www.hindawi.com
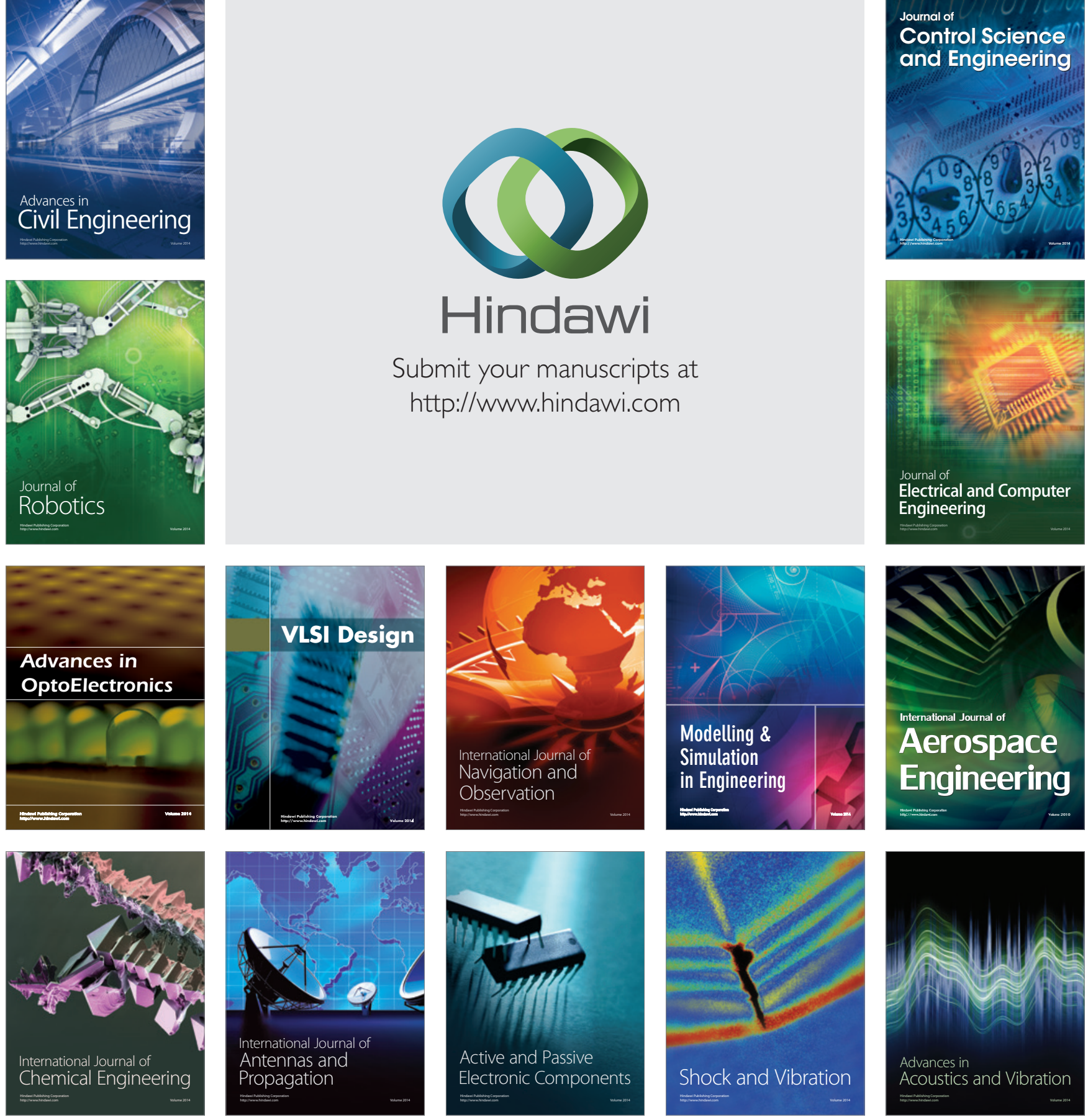